\title{
Relações Estado-Sociedade e ações de governabilidade, governança e accountability como desafios contemporâneos à democracia no Brasil
}

\section{State-Society relations and governability, governance and accountability actions as contemporany challenges to democracy in Brazil}

\author{
André Cutrim Carvalho ${ }^{1 *}$, Guilherme da Rocha Bezerra Costa ${ }^{2}$, David Ferreira Carvalho ${ }^{1}$
}

\begin{abstract}
RESUMO
O presente artigo tem como principal objetivo debater a relação Estado-Sociedade e ações de governabilidade, governança e accountability como desafios contemporâneos à democracia brasileira. Para alcançar este objetivo, o artigo utilizou de metodologia de pesquisa do tipo exploratória-qualitativa. A principal conclusão é de que criar, difundir e implementar melhorias na efetividade de estratégias de governabilidade, governança e accountability são fundamentais para a manutenção da democracia e o fortalecimento do desenvolvimento no Brasil. Isso é assim porque a consolidação da democracia que alcance a governabilidade no Brasil deve ser pensada em direta conexão com um verdadeiro projeto nacional de desenvolvimento e redução das desigualdades socioeconômicas. De fato, a consolidação democrática que alcance uma boa governabilidade e governança no Brasil, sem desvios de planejamento ou retóricas ideológicas, perpassa pela necessidade de melhoria da sua accountability. É, portanto, um avanço lento e gradual para uma sociedade mais evoluída que precisa ter "consciência" do que é importante para melhorar democraticamente enquanto nação.
\end{abstract}

Palavras-chave: Estado-Sociedade; Governabilidade; Governança; Accountability; Democracia.

\section{ABSTRACT}

The main objective of this article is to discuss the State-Society relationship and governability, governance and accountability actions as contemporary challenges to Brazilian democracy. To achieve this objective, the article used exploratory-qualitative research methodology. The main conclusion is that creating, disseminating and implementing improvements in the effectiveness of governability, governance and accountability strategies are essential for the maintenance of democracy and the strengthening development in Brazil. This is because the consolidation of democracy that achieves governability in Brazil must be thought of in direct connection with a true national project of development and reduction of socioeconomic inequalities. In fact, the democratic consolidation that achieves good governance and governance in Brazil, without deviations from planning or ideological rhetoric, permeates the need to improve its accountability. It is, therefore, a slow and gradual advance towards a more evolved society that is "aware" of what is important to improve democratically as a nation.

Keywords: State-Society; Governability; Governance; Accountability; Democracy.

\footnotetext{
${ }^{1}$ Universidade Federal do Pará - UFPA.

*E-mail: andrecc83@gmail.com

${ }^{2}$ Universidade Federal de Minas Gerais - UFMG.
} 


\section{INTRODUÇÃO}

Em linhas iniciais, pode-se compreender o Estado como uma organização política, socioeconômica e cultural, vista por muitos como a mais importante provedora de serviços públicos aos seus cidadãos, sobretudo quando faz uso do seu "poder" e de seus instrumentos de governança, governabilidade e accountability no âmbito de uma democracia. Na prática, porém, o Estado não é apenas uma simples relação de poder, mas a condensação material de uma relação de forças que possui uma ossatura específica que implica, para alguns dos seus aparelhos, a exclusão da presença física e direta das massas populares em sua interioridade.

A sociedade civil é representada no Estado pelo poder legislativo, mas pela visão ortodoxa a sociedade civil é composta por cidadãos dentro de um "arena" marcada pelo conflito de interesses. No Brasil, a Constituição de 1988 definiu o Estado Nacional como uma República Federativa, formada pela união indissolúvel dos Estados e municípios, constituindo-se assim em um Estado Democrático de Direito. O conceito de administração pública, no entanto, está imbricado ao de Estado e de Governo. Para Meirelles (1998, p. 65), a administração pública:

(...) em sentido formal, é o conjunto de órgãos instituídos para consecução dos objetivos do Governo, em sentido material, é o conjunto das funções necessárias aos serviços públicos em geral; em acepção operacional, é o desempenho perene e sistemático, legal e técnico, dos serviços próprios do Estado ou por ele assumidos em benefício da coletividade.

Assim, conforme Nogueira da Silva (1996, p. 42): “[Governo] é o conjunto de cargos políticos destinados exclusivamente ao exercício das deliberações executivas do Estado"; já para Castro (1936), quanto à definiç̧ão, a palavra "governo" costuma ser empregada vulgarmente como sinônimo de "poder executivo".

Nesse contexto, a accountability torna-se indissociável e demasiadamente importante para uma (boa) governança democrática, tanto do ponto de vista conceitual quanto sob o aspecto organizacional, institucional e operacional. Desta forma, criar, difundir e implementar melhorias administrativas-institucionais no âmbito da accountability constituem um grande desafio para a evolução da democracia no Brasil.

Isso é assim porque a responsabilização ou prestação de contas no país, dentro dos termos empregados pela accounttability, é essencial e principal indicativo de que os agentes do Estado - membros de órgãos administrativos e/ou representativos - precisam assumir o seu papel, enquanto gestores públicos, para efetivar uma governança com 
qualidade, transparência, eficiência, idoneidade e, acima de tudo, consciente de que agindo com desvio de função/finalidade serão alcançados pela legislação vigente, órgãos de controle e pela própria vigilância da sociedade civil organizada, o que pode resultar em sérios problemas de governabilidade.

O presente artigo tem como principal objetivo, portanto, debater a relação Estado-Sociedade e ações de governabilidade, governança e accountability como desafios contemporâneos à democracia brasileira. Para alcançar este objetivo, o artigo utilizou de metodologia de pesquisa do tipo exploratória-qualitativa. De acordo com Gil (1991 apud Silva e Menezes, 2005, p. 83):

[A] pesquisa exploratória visa proporcionar maior familiaridade com o problema com vistas a torná-lo explícito ou a construir hipóteses. Envolve levantamento bibliográfico; (...) análise de exemplos que estimulem a compreensão. Assume, em geral, as formas de Pesquisas Bibliográficas e Estudos de Caso.

$\mathrm{O}$ artigo buscará o maior número possível de informações sobre as temáticas utilizando a técnica de pesquisa do tipo qualitativa. Para Silva e Menezes (2005, p. 20):

[A pesquisa qualitativa] considera que há uma relação dinâmica entre o mundo real e o sujeito, isto é, um vínculo indissociável entre o mundo objetivo e a subjetividade do sujeito que não pode ser traduzido em números. A interpretação dos fenômenos e a atribuição de significados são básicas no processo de pesquisa qualitativa. Não requer o uso de métodos e técnicas estatísticas. (...) O processo e seu significado são os focos principais de abordagem.

Dito isso, este artigo foi estruturado em quatro seções, além desta seção introdutória, à saber: na segunda seção é apresentado a relação Estado-Sociedade em meio as ações de governabilidade, governança e accountability como desafios contemporâneos à democracia; na terceira seção são discutidos os princípios da accountability em torno da organização, das limitações e das definições de poderes numa federação, além das dimensões da accountability e suas principais implicações; por último, na quarta seção, as considerações finais.

\section{RELAÇÃO ESTADO-SOCIEDADE E AÇÕES DE GOVERNABILIDADE, GOVERNANÇA E ACCOUNTABILITY: DESAFIOS CONTEMPORÂNEOS À DEMOCRACIA}

Uma das tendências das relações Estado-Sociedade situa-se no clamor, quase consensual, para a criação de uma nova relação institucional na qual a sociedade civil deve cumprir um papel mais ativo e relevante. Entretanto, analisando-se os conteúdos das várias propostas de uma nova forma de rearticulação das relações Estado-Sociedade, 
constata-se que um suposto consenso tende a se dispersar em demandas que vão desde a privatização de atividades econômicas estatais, perpassando pelas relações de parcerias público-privadas, até o retorno à estatização fundada em um aparente "consenso" político construído por formas sociais participativas de forte teor ideológico.

Em Gramsci (1996), a sociedade civil articula-se em dois grandes planos superestruturais: o que é chamado sociedade civil, pois compreende o conjunto de organismos ditos privados; e o da sociedade política ou Estado. Assim, segundo Gramsci (1978) e Bobbio (1982), é a sociedade civil - e não a sociedade política (Estado) -, como em Hegel, a principal força que representa o momento ativo e positivo do desenvolvimento histórico de uma nação.

De tal modo, o despertar da consciência política da sociedade sobre o seu papel como ator importante das transformações sociais pode mitigar a dominação dos grupos sociais de interesses particulares que não levam em conta os interesses gerais. $O$ significado do Estado-integral gramsciano (Estado mais sociedade civil) ganha contornos bem atualizados: de um lado, tem-se um forte apelo às sinergias da associação privada, baseada na valorização da eficiência empresarial; de outro, tem-se as muitas referências da participação democrática, o que, por carecer de conteúdos claros, não basta para designar um princípio valorativo que fundamente o desenvolvimento do poder da sociedade civil.

Entretanto, a incessante busca pela ampliação da democracia política e social é uma diretriz básica para a rearticulação das relações Estado-Sociedade que incorpore um novo significado sócio-político quanto à capacidade de auto-organização social de uma sociedade pluralista. Assim, em um contexto da globalização, os antigos métodos de fazer política, ancorados no fisiologismo dos partidos políticos e nas abusivas práticas de privatização dos recursos públicos, deverão ser abandonadas.

Isto significa que a democracia brasileira precisa ser revitalizada para enfrentar os novos problemas socioeconômicos e, neste caso, os processos de governabilidade, governança e accounntability requerem o afastamento das lógicas auto referenciais do carcomido sistema político-estatal para ceder espaço à um sistema político-institucional que, além de abrigar as distintas formas de representação social, possa reconstruir a ordem social, hoje abalada pelo aumento da pobreza social e a crise econômica. Carvalho (2021, p. 46-47) afirma que:

À crescente (des)legitimação do Estado e das instituições políticas devem ser adicionados outros fatos sociais relevantes - como, por 
exemplo, a crescente desintegração social definida pelos altos índices de pobreza e de desemprego - associados às mutações dos mais variados tecidos sociais.

A dificuldade de articular alianças políticas não-espúrias e o recurso sistemático a formas não negociadas de administração do conflito social distributivo, quanto à partilha federativa dos recursos fiscais, remonta ao período de transição do modelo agroexportador-rural para o modelo industrial-urbano. No Brasil, o Estado Novo contribuiu consideravelmente para a formação da burguesia mercantil dependente do erário público e preservou o poder político da oligarquia patrimonialista de que fala Faoro (1987) em “Os Donos do Poder".

A constituição de 1988, por sua vez, criou um arcabouço institucional que veio acomodar os interesses da burguesia mercantil e da oligarquia regional, dependentes dos recursos do Estado, com a montagem de um novo arcabouço institucional que combinou um presidencialismo forte e centralizador pari passu com um parlamento comprometido com os grupos de interesse particulares, e não com os interesses universais da sociedade.

$\mathrm{Na}$ prática, o fortalecimento da sociedade civil para enfrentar o neocorporativismo que instaurou-se dentro do aparelho de Estado, depende dos processos de consolidação da democracia e da cidadania, bem como dos instrumentos e limites da accountability, o que implica conduzir uma estratégica de luta pela própria democratização do Estado nas dimensões estruturais dos três poderes: executivo, legislativo e judiciário, sem esquecer da esfera privada.

Além disso, o hiato entre uma institucionalização estatal rígida, com fraco potencial de incorporação política das demandas sociais, bem como uma estrutura social crescentemente diferenciada, tem aprofundando as tensões sociais ligadas ao processo de modernização institucional no Brasil.

No contexto da crise do atual Estado brasileiro e, sobretudo, para repensar a reforma do Estado, é pertinente recorrer às categorias da ciência política de governabilidade e governança. Destarte, a governabilidade refere-se às condições gerais sob as quais manifesta-se à ação do Estado em uma sociedade pautada pela democracia. Essas condições, entretanto, dependem do regime político (democrático ou autoritário); das relações entre os poderes executivo, legislativo e judiciário (maior ou menor assimetrias); da forma de governo (parlamentarismo ou presidencialismo); do sistema partidário (pluripartidário ou bipartidário); do sistema de intermediação dos interesses dos grupos sociais (corporativistas ou pluralistas), dentre outras mais. 
Na concepção de Carvalho (2021, p. 128):

Isto requer uma tripla atenção do Estado brasileiro para: $1^{\circ}$ ) lidar com os problemas da economia doméstica relativa ao crescimento com distribuição de renda; $2^{\circ}$ ) superar os impasses da inserção desta economia doméstica na economia global, o que envolve uma (re)definição de prioridades em termos de políticas públicas, gestão ambiental e, sobretudo, de governabilidade democrática; e $3^{\circ}$ ) instaurar um planejamento estratégico exequível para a promoção de um desenvolvimento que possa agregar valor aos produtos comercializados na região, propiciando com isso uma verticalização na produção e rompendo, de uma vez por todas, com o fardo que é ser uma economia de enclave.

Cabe ressaltar que não há uma fórmula mágica capaz de assegurar uma boa governança e governabilidade, já que distintas combinações institucionais podem produzir condições mais ou menos favoráveis à sua existência, pois como indica Carvalho (2007 apud Carvalho, 2012, p. 62):

(...), a governabilidade deve ser entendida como a capacidade sóciopolítica de um governo democrático procurar não só viabilizar acordos ou pactos políticos partidários para dar sustentação à implementação de um determinado projeto de desenvolvimento nacional, mas também enfrentar os desafios e aproveitar as oportunidades para concretizar o pacto social visando à melhoria do bem estar social.

Neste cenário, segundo Carvalho (2012, p. 62), por governança:

(...) deve ser entendido como sendo a capacidade governativa do Estado, tomada em sentido amplo, o que envolve sua capacidade de gestão governamental na formulação e implementação das suas políticas públicas e na consecução de metas coletivas. Do ponto de vista institucional, o conceito de governança refere-se ao conjunto de mecanismos e procedimentos para lidar com a dimensão participativa e plural da sociedade, o que implica a necessidade para se expandir e aperfeiçoar os meios de interlocução e de administração do jogo político de interesses.

De fato, a governabilidade é, por conseguinte, um conceito diferente do conceito de governança ou sistema institucional - formal ou informal - que demarca a ação dos atores sociais - governamentais e não-governamentais - relevantes para a determinação e a alocação dos bens e recursos públicos para a sociedade. Assim, segundo MatiasPereira (2010, p.109):

O termo governança surge tendo como referência a concepção de bom governo (good government) e na competência do Estado de executar de forma consistente as políticas públicas. A partir da intensificação de seu debate no âmbito acadêmico, a noção de governança passa a incorporar outras variáveis - além daquelas relacionadas ao bom desempenho da administração pública, em particular a atuação da sociedade civil como ator político. Nessa nova concepção, a ideia de hierarquia, como princípio organizador e da relação Estado e sociedade, transforma-se numa reação de cooperação e colaboração entre Estado e sociedade civil. 
O conceito de governabilidade é diferente de ação de governar (governing), que compreende tanto a ação de fazer política quanto a ação de formular e implementar boas políticas públicas e a própria gestão pública. Para Rhodes (1996, p. 652-653):

A partir dos sentidos da palavra "governo", como atividade ou processo de governar, condição de normas ordenadas e forma, método ou sistema pelo qual uma determinada sociedade é governada, se estabelece o conceito de "governança" como uma mudança no sentido do governo, referindo-se a um novo processo de governar, ou uma condição alterada da regra ordenada, ou o novo método pelo qual a sociedade é governada.

Isso é assim porque, em conformidade com Denhardt et al. (2000), o papel do governo é transformado para a função de controlar a configuração da agenda, trazendo os “jogadores” adequados para a mesa, por meio de coalizões com agências públicas, organizações privadas e sem fins lucrativos, além das funções de facilitação, negociação e intermediação para alcançar as soluções dos problemas públicos.

\section{ORGANIZAÇÃO, LIMITAÇÕES E DEFINIÇÕES DE PODERES NUMA FEDERAÇÃO: PRINCÍPIOS DA ACCOUNTABILITY}

John Locke, em meados do século XVII, apresenta a base estrutural para o debate que existe hoje acerca da accountability. Locke (1973, p. 92) estabelece que “(...) a primeira lei positiva e fundamental de todas as comunidades consiste em estabelecer o poder legislativo". Com isso, fica explícita a necessidade de preservar a sociedade civil de qualquer indivíduo com a possibilidade de obter, para si ou outrem, poder absoluto.

Em outras palavras, o poder é da sociedade, de todos os seus membros e quem governa não pode ter para si a liberdade de criar as leis que regem a nação. Desta forma, como o poder deve pertencer a sociedade, aqueles que criam as leis (o legislativo) devem ser eleitos pela sociedade, assim como o direito de criar leis deve ser intransferível.

Locke buscava delinear a separação entre o poder legislativo e o poder executivo por acreditar que o poder absoluto não traria para a sociedade, como um todo, os benefícios que um poder independente eleito pela nação poderia trazer. Para Locke (1973, p.99): “(...) cabe ainda ao povo um poder supremo para afastar ou alterar o legislativo quando é levado a verificar que age contrariamente ao encargo que lhe confiaram".

Locke (1973, p. 96) separa o poder em legislativo, executivo e federativo, para que as necessidades da sociedade possam ser atendidas de forma igualitária, à saber:

Primeiro, [o legislativo] têm de governar por meio de leis estabelecidas e promulgadas, que não poderão variar em casos particulares, instituindo a mesma regra para ricos e pobres, para favoritos na corte ou camponeses no arado; Segundo, tais leis não devem ser destinadas a 
qualquer outro fim senão o bem do povo; Terceiro, não devem lançar impostos sobre a propriedade do povo sem o consentimento deste, dado diretamente ou por intermédio dos seus deputados. Quarto, o legislativo não deve nem pode transferir o poder de elaborar leis a quem quer que seja, ou colocá-lo em qualquer lugar que não o indicado pelo povo.

Nesse contexto, Norberto Bobbio (1984) discorre sobre a necessidade de limitar

o poder estatal ao apontar três teorias para acabar com o poder absoluto, que não reconhece ninguém superior e que foram formadas no início da idade moderna. São elas: $\left.1^{\circ}\right)$ Reconhecimento dos direitos naturais; $2^{\circ}$ ) Separação dos poderes; e $3^{\circ}$ ) Soberania popular, isto é, dar o poder à quem dele não pode abusar, ou seja, ao povo.

Limitar o poder se faz necessário, segundo Bobbio (1984), pois o poder absoluto traz consigo a possibilidade do abuso de poder. Os direitos naturais são fatores limitantes externos e, devem ser reconhecidos, segundo o autor, pois estes precedem o Estado. Bobbio (1984) procurou apresentar a separação do poder como uma alternativa a necessidade de reconhecimento dos direitos naturais da sociedade. Por certo, a separação do poder é um limite interno a soberania do Estado.

Da mesma forma que Locke apresentou a divisão do Estado, Bobbio (1984, p. 16, grifo nosso) estabeleceu a sua da seguinte forma:

Teoria da separação dos poderes. Existem outras teorias que impõem ao Estado limites internos: independentemente do fato que o poder estatal tenha que deter-se frente a direitos preexistentes ao Estado, as mesmas sustentam que a melhor maneira de limitar este poder é quebrálo. Trata-se de conseguir que: a) a massa do poder estatal não seja concentrada numa só pessoa, mas distribuída entre diversas pessoas; b) que as diferentes funções estatais não sejam confundidas num só poder, mas sejam atribuídas a órgãos distintos. Segundo essa teoria, o limite do poder nasce da sua própria distribuição, por duas razões: 1) não existirá mais uma só pessoa que tenha todo o poder, mas cada uma terá somente uma porção do mesmo; 2) os órgãos distintos aos quais serão atribuídas funções distintas se controlarão reciprocamente (balança ou equilíbrio dos poderes) de maneira que ninguém poderá abusar do poder que lhe foi confiado. Se se consideram como funções fundamentais do Estado a função legislativa, a executiva e a judiciária, a teoria da separação dos poderes exige que existam tantos poderes quantas são as funções e que cada um dos poderes exerça uma só função, assim que possa surgir o Estado desejado por essa teoria, Estado que foi também chamado de Estado Constitucional, quer dizer aquele Estado no qual os poderes legislativo, executivo e judiciário são independentes um do outro e em posição tal que podem controlar-se reciprocamente.

Com isto, defende-se a proposição de que as diferentes esferas de governo se controlarão reciprocamente. Diante disso, é preciso criar tantas divisões quanto atribuições de poder. Este tipo de Estado o autor Norberto Bobbio classificou-o de Estado Constitucional, no qual os diferentes poderes são independentes um do outro e em posição tal que podem controlar-se reciprocamente. 
A teoria da soberania popular é proposta pelas teorias democráticas. Ao invés de limitar o poder interna ou externamente, como proposto acima, deve-se almejar a participação de todos os cidadãos. Com isto, ao invés de limitar, dilui-se o poder. Nas palavras de Rousseau, parafraseadas por Bobbio (1984, p.16), “(...) pertencendo a todos é como se não pertencesse totalmente a ninguém".

Como foi dito anteriormente, que o bem da sociedade deve ser o objetivo final das ações do Estado, não se pode conceber que a sociedade realizará medidas contra ela, ou seja, a sociedade não pode abusar do poder. Peters (1995), no Livro "The Politics of Bureaucracy", apresenta os conceitos básicos de accountability, ética, controle e responsabilidade, bem como discorre acerca dos diferentes instrumentos e limites da accountability.

Peters (1995) divide os instrumentos de accountability em cinco: $1^{\text {o) }}$ ) Organizacionais; $2^{\circ}$ ) O mercado e outros controles externos; $3^{\circ}$ ) Pressão pública e grupos; $4^{\circ}$ ) Político; e $5^{\circ}$ ) Restrições normativas. Logo, usar organizações como um instrumento de accountability consiste, basicamente, em permitir que servidores públicos se policiem nos termos contemporâneos. O referido autor divide em dois os métodos, denominados de publicidade e disciplina interna, para "limitar o poder" dos indivíduos ou organizações para a tomada de decisões, ou para o rumo político ou privado da instituição em questão.

No caso da "publicidade", o importante é que a organização tenha a capacidade de corrigir qualquer erro exposto ao público geral, ou melhor, a transparência nas decisões e rumos empresariais (públicos também) pode trazer uma maior responsabilidade, em especial de fazer certo da primeira vez, e quando isto não for possível, de corrigir erros de maneira satisfatória; já a "disciplina interna" é outra forma de controle administrativo que não sucumbe a imposição externa de controle, que tem como característica ter um indivíduo responsável pela supervisão que tem à disposição alguns tipos de sansões ao comportamento indesejado de indivíduos.

Outra forma de controle administrativo é o controle externo exercido por mercados ou quase-mercados. Nestas circunstâncias, uma determinada instituição, ao invés de usar controles contábeis ou controles de orçamento, pode optar por colocar esse serviço para competição externa, aumentando assim a sua transparência. O problema com esta abordagem é o caráter da maximização da eficiência, e não tanto do melhor para a sociedade ou clientes de uma determinada empresa. 
Ademais, a pressão pública, ou de grupos de interesse, pode ser importante para limitar ou direcionar as ações de uma instituição. A voz popular, organizada ou não, pode "forçar" ações de responsividade, legislativa ou administrativa, de uma empresa ou governo, passando a servir como um check and balance para a instituição em foco.

Por outro lado existem métodos de controle políticos, por meio de instituições políticas, para "direcionar" as ações institucionais e organizacionais. Peters (1995) divide este método em três subcategorias, sendo que na categoria legislativa tem-se seis formas de accountability. São elas:

$\left.1^{\circ}\right)$ A responsabilidade ministerial, na qual um Ministro é responsável pelas ações do seu ministério e funcionários, colocando desta forma uma obrigação de atenção sobre o "chefe";

$2^{\circ}$ ) O controle através do orçamento, que pode impactar quantos ou quais funcionários podem trabalhar em uma dada instituição;

$3^{\circ}$ ) Uma investigação, desde perguntas administrativas até Comissões Parlamentares de Inquérito (CPIs), ou mesmo a utilização de um ombudsmen (ouvidor);

$4^{\circ}$ ) O serviço eleitoral, no qual a legislativo demonstra a possibilidade da sociedade civil ter um representante, que atue como intermediário entre a sociedade civil organizada e o meio político, para apresentar as necessidades urgentes de um grupo ou da sociedade como um todo;

$\left.5^{\circ}\right)$ Revisão da legislação secundária, na qual o legislativo imbui-se do direito de veto para certas regulamentações; e

$6^{\circ}$ ) Pós-auditoria, na qual a legislatura aloca recursos para fins específicos e, desta forma, tem a certeza que o executivo está usando os recursos de forma apropriada.

Já a categoria executiva divide-se em cinco:

$\left.1^{\circ}\right)$ Poderes pessoais: caracterizando-se pelo poder em nomear e remover funcionários;

$2^{\circ}$ ) Investigação: o poder judiciário que pode investigar atividades administrativas;

$3^{\circ}$ ) Reorganização: é o poder de reorganizar o governo como uma forma de estabelecer o controle executivo;

$4^{\circ}$ ) Poderes fiscais: caracteriza-se pela discricionariedade que pode ser exercida, a princípio, pelo Poder Executivo Federal, Estadual e Municipal sobre o orçamento disponível de uma instituição ou ministério; podendo exercer "veto de item" sobre a forma pela qual os recursos disponibilizados pela união podem ser utilizados; e 
$5^{\circ}$ ) Gabinetes e conselheiros ministeriais: um controle sobre o lado da entrada do papel do serviço público em uma democracia moderna. Neste caso, um Ministro tem ao seu lado pessoas com ideais políticos similares ao dele para servirem de "consultores", ao invés de um membro da sociedade ao qual ele não escolheu como seu assessor.

Cabe destacar que o judiciário é um importante poder burocrático, pois baseiase no poder da sociedade civil em reivindicar uma prestação de contas ou punição contra uma ação institucional. Isso posto, o controle normativo se notabiliza por ser a forma mais adequada de controle sobre a burocracia, já que toma forma antes do problema surgir, sendo ainda de baixo custo e confiável.

\section{DIMENSÕES DA ACCOUNTABILITY E SUAS PRINCIPAIS IMPLICAÇÕES}

De início, Brinkerhoff (2001) começa o seu argumento expondo três questões chaves: como o poder e a autoridade são alocados nas diferentes esferas públicas? O que garante que os funcionários públicos irão utilizar seu poderes e a sua autoridade institucional de forma correta e responsável? E o que é accountability?

As duas primeiras questões entrelaçam-se perfeitamente com as discussões provenientes das seções anteriores, enquanto a última ajuda a entender o que o John Locke, Norberto Bobbio e Guy Peters apresentam. Brinkerhoff (2001) começa definindo as implicações do significado de accountability e as divide em quatro pontos cruciais:

$1^{\circ}$ ) Resposividade: ser accountable, ou melhor, ser responsável, significa ter a obrigação de responder as questões relacionadas à tomada de decisões, sejam elas do que foi feito (transparência), ou do por que foi feito (razões);

$2^{\circ}$ ) Punição a infração: ser accountable é poder sofrer punições, definidas por lei ou geradas pelo mercado, quando a boa conduta for quebrada;

$3^{\circ}$ ) Accountability vertical (fora do Estado) ou horizontal (dentro do Estado);

$4^{\circ}$ ) Tipologias de accountability, as que possuem grande ou pequena capacidade de impor suas punições. Tanto a accountability vertical quanto a accountability horizontal possuem tipologias distintas. Exemplos de grande capacidade de impor punições: agências controladoras ou anticorrupção, comitês legislativos, eleições, agências reguladoras internacionais/nacionais de padronização. Exemplos de pequena capacidade de impor punições: ombudsman (ouvidor), leis de liberdade de informação, jornalismo investigativo, comitês civis de fiscalização, etc. 
O Quadro 1, em concordância com Brinkerhoff (2001, p. 06, tradução nossa), discorre sobre as principais dimensões, definições e links para outras dimensões da accountability:

Quadro 1 - Dimensões da accountability, definições e links

\begin{tabular}{|c|c|c|}
\hline $\begin{array}{l}\text { Dimensão da } \\
\text { Accountability }\end{array}$ & Definição & Links para outras dimensões \\
\hline $\begin{array}{c}\text { Democrática/ } \\
\text { Política }\end{array}$ & $\begin{array}{l}\text { Supervisão de } \\
\text { funcionários } \\
\text { públicos e de agências } \\
\text { em termos de sua } \\
\text { capacidade de } \\
\text { resposta aos líderes } \\
\text { políticos e aos } \\
\text { cidadãos; e de } \\
\text { cumprimento da } \\
\text { confiança pública. }\end{array}$ & $\begin{array}{l}\text { Para o financeiro: funcionários } \\
\text { e agências de orçamento para cumprir seus } \\
\text { mandatos públicos. Além disso, o diálogo } \\
\text { e a deliberação sobre os orçamentos } \\
\text { são características fundamentais do } \\
\text { discurso democrático e de políticas. } \\
\text { Para o desempenho: prestação de } \\
\text { serviços e resultados é uma manifestação } \\
\text { concreta da capacidade de resposta aos } \\
\text { cidadãos interesses e necessidades da } \\
\text { sociedade. Julgamentos sobre } \\
\text { desempenho do comportamento do } \\
\text { eleitor influência. }\end{array}$ \\
\hline Financeira & $\begin{array}{l}\text { Exame do } \\
\text { cumprimento dos } \\
\text { funcionários } \\
\text { e agências com as leis, } \\
\text { regulamentos e } \\
\text { procedimentos para a } \\
\text { alocação transparente, } \\
\text { das despesas e } \\
\text { relatórios de recursos } \\
\text { financeiros. }\end{array}$ & $\begin{array}{l}\text { Para a democrática: a responsabilização } \\
\text { financeira assegura que os recursos sejam } \\
\text { utilizados para fins públicos } \\
\text { acordados. Ademais, transparência } \\
\text { na prestação } \\
\text { contas financeira aumenta a capacidade } \\
\text { dos cidadãos de participarem na } \\
\text { fiscalização. } \\
\text { Para o desempenho: bens e serviços não } \\
\text { podem ser produzidos sem recursos } \\
\text { financeiros. De fato, muitos sistemas de } \\
\text { accountability juntam accountability } \\
\text { financeira e de desempenho. }\end{array}$ \\
\hline Desempenho & $\begin{array}{l}\text { Fiscalização das ações } \\
\text { dos funcionários e } \\
\text { agências relacionadas } \\
\text { com a produção de } \\
\text { resultados, prestação } \\
\text { de serviços, } \\
\text { realizações } \\
\text { de objetivos } \\
\text { e obtenção de } \\
\text { resultados e impactos. }\end{array}$ & $\begin{array}{l}\text { Para a democrática: políticos e } \\
\text { cidadãos olham o desempenho para } \\
\text { determinar se o governo é sensível, } \\
\text { confiável, eficaz e democrático. Estas } \\
\text { determinações podem afetar a satisfação } \\
\text { do cidadão com o governo e os resultados } \\
\text { das eleições. } \\
\text { Para o financeiro: links de desempenho e } \\
\text { gastos de recursos financeiros para } \\
\text { alcançar resultados desejados. }\end{array}$ \\
\hline
\end{tabular}

Fonte: Brinkerhoff (2001, p. 06, tradução e adaptação nossa).

Desta forma, Brikerhoff (2001) consegue expandir suas questões iniciais aos responder outros dois questionamentos: quem é Accounbtable? e Accountable para quem? Essas dúvidas podem ser respondidas, resumidamente, por meio do Quadro 2: 
Quadro 2 - Accountables: quem, por e para quem?

\begin{tabular}{|c|c|c|}
\hline Quem é Accounbtable? & Accountable por: & $\begin{array}{c}\text { Accountable para } \\
\text { quem? }\end{array}$ \\
\hline $\begin{array}{c}\text { Políticos e líderes políticos } \\
\text { nomeados. }\end{array}$ & $\begin{array}{c}\text { Democrático/Político com um } \\
\text { forte link ao desempenho. }\end{array}$ & $\begin{array}{c}\text { Entidades } \\
\text { controladoras do } \\
\text { Estado; cidadãos e } \\
\text { sociedade civil; } \\
\text { público especial e } \\
\text { grupos marginalizados } \\
\text { ou excluídos e; atores } \\
\text { internacionais. }\end{array}$ \\
\cline { 1 - 2 } $\begin{array}{c}\text { Funcionários públicos e } \\
\text { agências. }\end{array}$ & Financeiro e Desempenho. \\
\hline $\begin{array}{c}\text { Atores não-governamentais: } \\
\text { ONGs, setor privado, } \\
\text { cidadãos. }\end{array}$ & $\begin{array}{c}\text { Democrático/Político, Financeiro } \\
\text { e Desempenho. }\end{array}$ & \\
\hline
\end{tabular}

Fonte: Elaboração própria.

Brinkerhoff (2001) oferece outras opções para aumentar/melhorar as ações em torno da accountability. Pode-se visualizar as sugestões do autor através da Figura 1:

Figura 1 - Estratégias de melhorias da accountability

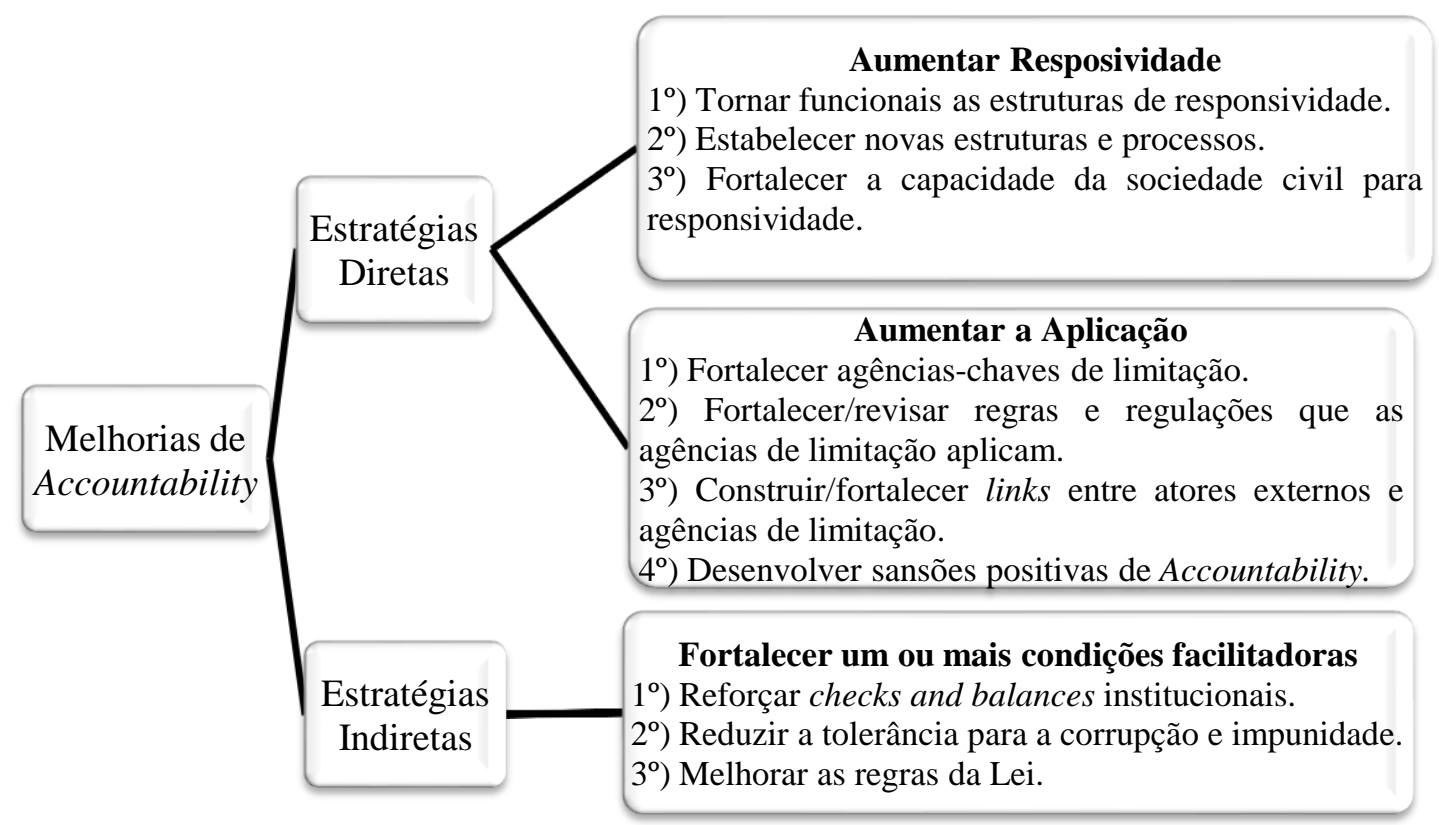

Fonte: Brinkerhoff (2001, p. 06, tradução e adaptação nossa).

Nesse contexto, levando em consideração que o Estado realiza políticas públicas que costumam impactar diretamente no mercado de trabalho, de forma responsável e apto para "responder" a nação, pode-se analisar a situação do mercado de trabalho brasileiro e contrapor, de forma não exaustiva, com a realidade político-social do Brasil como exemplo prático. 
Uma das principais medidas que o poder executivo pode tomar, de forma periódica, e que impacta no mercado de trabalho, é a fixação da taxa básica de juros (SELIC). Isso é assim porque o Banco Central (BACEN) ${ }^{3}$ é um órgão independente, mas que sofre constante pressão dos mais diversos grupos sociais - mídia, política, sindicatos, uniões e sociedade civil organizada - e, por conta disso, deve comporta-se da forma mais idônea possível.

$\mathrm{Na}$ realidade, a sua idoneidade é mantida pela forma como a decisão de estabelecer a SELIC é tomada, ou seja, através de uma reunião na qual os participantes votam (para estabelecer um valor à taxa) abertamente e têm a possibilidade de exporem os motivos para seus votos. Não só isso, após todas as reuniões é divulgada a ata da mesma ao público geral, com o detalhamento dos motivos pelos quais as medidas foram tomadas, em uma clara tentativa de justificar sua decisão, mas acima de tudo, de demonstrar a sua lisura.

Não fosse transparente a forma pela qual a SELIC é estabelecida, o Brasil não teria um mercado de crédito confiável e previsível ${ }^{4}$. Além do mais, não seria possível traçar um planejamento industrial e, por consequência, um planejamento da federação sobre políticas de incentivo ao trabalho (in)formal. Isto pois, sem um planejamento industrial privado claro ao Estado, não se pode antecipar decisões ou lançar políticas críveis.

Desta forma, tratando exclusivamente de uma única variável que pode vir a impactar o mercado de trabalho brasileiro e o crescimento econômico do país, pode-se vislumbrar o papel fundamental da accountability sobre este tema da seguinte forma: $1^{\text {}}$ ) Separação de poder entre Estado e Banco Central, mesmo não sendo completa; $2^{\circ}$ ) Transparência através das atas do COPOM; $3^{\circ}$ ) Pressões externas e internas em torno dos diferentes membros do conselho e diferentes grupos da sociedade com divergentes opiniões sobre o tema; $4^{\circ}$ ) Responsabilidade financeira, já que as decisões do COPOM afetam o dia a dia, tanto da sociedade quanto do Estado através do mercado de crédito e da dívida pública; $5^{\circ}$ ) Limitação de poder, até porque não é um indivíduo que toma a decisão, mas um grupo de indivíduos com peso decisório igual entre eles; e $6^{\circ}$ )

\footnotetext{
${ }^{3}$ O Banco Central é o órgão executivo que segue as normas fixadas pelo Conselho Monetário Nacional (CMN) para o Sistema Financeiro Nacional (SFN). Ele executa as diretrizes emanadas do CMN para todo o SFN brasileiro.

${ }^{4}$ Previsível no sentido dos cálculo de contratos, não de variações de taxas de juros entre reuniões do COPOM.
} 
Intolerância à corrupção, pois o último resquício de um Banco Central não independente é o poder do Presidente da República em demitir o presidente do Banco Central, portanto qualquer dúvida em relação a tomada de decisões, para benefício próprio ou de grupos de interesses, tem repercussões bastante claras.

Deste modo, fica clara a importância da transparência e do engajamento da sociedade nas tomadas de decisões do Estado. A fiscalização - atrelada a regras claras de punição ao erro, ou a má conduta - é indispensável para a boa consecução de políticas públicas em prol do desenvolvimento do país, ou seja, para que os resultados das ações do Estado beneficiem a sociedade como um todo e não somente a grupos de interesses.

As atas do COPOM representam uma das ações mais nítidas do Estado brasileiro em responder a sociedade sobre um de seus atos, demonstrando o compromisso de sua governança com a transparência e o bem da nação em termos de governabilidade, mesmo que as decisões do conselho não aparentem ser as mais condizentes para os mais distintos grupos de interesse.

\section{CONSIDERAÇÕES FINAIS}

O presente artigo procurou demonstrar que o aumento da accountability pode ser um elemento-chave no amplo espectro de mudanças institucionais de um país, desde o nível nacional até as campanhas anticorrupção ou de descentralização da máquina administrativa. Logo, a accountability é inseparável da governança democrática, tanto conceitualmente quanto operacionalmente.

A consolidação democrática que alcance a governabilidade no Brasil deve ser pensada em conexão direta com um verdadeiro projeto nacional de desenvolvimento e redução das desigualdades sociais. Mas, como a democracia supõe a busca de uma compatibilização negociada dos meios escassos aos fins sociais pretendidos, isto implica no resgate da noção do interesse público, o que não necessariamente se confunde com o interesse nacional.

Nestes termos, criar, difundir e implementar melhorias na efetividade de estratégias de governabilidade, governança e accountability, são, portanto, fundamentais para manter a democratização e fortalecer o desenvolvimento do país. Ficam então duas questões: de onde vem o ímpeto por mudança(s)? Como as reformas se resolverão com os inevitáveis conflitos? Um país apto em responder estas questões, sem desvios de 
planejamento ou retóricas ideológicas, certamente estará no caminho correto para melhorar a sua accountability e, assim, o seu processo de desenvolvimento democrático.

Diante disso, consolidar algumas lições para melhorar a governança lado-a-lado com a accountability nacional é imprescindível, em especial para desenvolver legitimidade para o tema em questão; construir uma "ponte" entre a sociedade civil organizada e o governo para que possam surgir "campeões" da accountability; alocação correta de recursos com metas e timeframes (prazos); e monitorar o progresso com forte foco na responsividade - até porque a mesma não surge espontaneamente - para a sociedade e a flexibilidade em busca de mudanças.

É necessário, deste modo, planejamento e significativo engajamento de diferentes esferas públicas, econômicas e sociais. É, portanto, um avanço lento e gradual para uma sociedade mais evoluída que tem "consciência" do que é importante para melhorar democraticamente enquanto nação.

\section{REFERÊNCIAS}

BOBBIO, N. O conceito de sociedade civil. Rio de Janeiro, Graal, 1982.

BOBBIO, N. Direito e Estado no Pensamento de Kant. Brasília, Editora UnB. 1984.

BRINKERHOFF, D. W. Taking Account of Accountability: A Conceptual Overview and Strategic Options. 2001.

CARVALHO, A. C. Expansão da Fronteira Agropecuária e a Dinâmica do Desmatamento Florestal na Amazônia Paraense. Campinas, SP. Tese de Doutorado Universidade Estadual de Campinas, Instituto de Economia, 2012.

CARVALHO, A. C. A dinâmica do capital e o avanço da fronteira no Pará: uma perspectiva de compreensão histórica a partir da "Operação Amazônia" em 1966-1979. Belém, PA. Dissertação de Mestrado - Universidade Federal do Pará, Programa de PósGraduação em História, 2021.

CARVALHO, D. F. Estado, Governabilidade e Governança. Belém, Anais do 59a Congresso Anual da SPPC. Belém-PA, SPBC, 2007.

CASTRO, A. A Nova Constituição brasileira. Imprenta: RJ, Freitas Bastos, 1936.

DENHARDT, R. B.; DENHARDT, J. V. The New Public Service: Serving Rather than Steering. Public Administration Review. Arizona State University, Vol. 60, No. 6, p. 549-559, 2000.

FAORO, R. Os donos do poder. Rio de Janeiro, Globo, 1987. 
GIL, A. C. Como elaborar projetos de pesquisa. São Paulo: Atlas, 1991.

GRAMSCI, A. Obras escolhidas. São Paulo, Martins Fontes, 1978.

GRAMSCI, A. Lettere dal Carcere. Ed. A. Santucci. Palermo, Ed. Sellerio, 2 v., 1996.

LOCKE, J. Carta Acerca da Tolerância. Tradução de Anoar Aiex. São Paulo: Abril Cultural, 1973. (Coleção Os Pensadores).

MATIAS-PEREIRA, J. A Governança Corporativa aplicada no setor público brasileiro. Administração Pública e Gestão Social, [S. l.], v. 2, n. 1, p. 109-134, 2010. Disponível em: https://periodicos.ufv.br/apgs/article/view/4015. Acesso em: 27 jan. 2022.

MEIRELLES, H. L. Direito Administrativo Brasileiro. 23 ed. São Paulo: Malheiros Editores, 1998.

NOGUEIRA DA SILVA, P. N. Curso de direito constitucional. Imprenta: São Paulo, Revista dos Tribunais, 1996.

PETERS, G. B. The Politics of Bureaucracy. New York, Ed. Routledge, 1995.

RODHES, R. A. W. The new governance: governing without government. Political Studies, vol. 44, nº 4, 1996, p. 652-667.

SILVA, E. L. da; MENEZES, E. M. Metodologia da pesquisa e elaboração de dissertação, UFSC, 4 ed. Ver. Atual. Florianópolis, 2005. 